\title{
Injuries due to falls as a result of uneven pavements
}

\author{
M. T. HUNT, M. CHAPMAN \& G. LLOYD
}

Accident and Emergency Department, King's College Hospital, London

\section{SUMMARY}

At least one person per day attending the A\&E department at King's College Hospital has sustained injuries from uneven pavements. The injuries have a significant morbidity as well as a mortality of $1 \%$. A\&E records can be a source of useful information to aid local authorities in identifying areas associated with these injuries in order to reduce their frequency and subsequent claims for compensation.

\section{INTRODUCTION}

At least one person per day attending the Accident and Emergency (A\&E) department at King's College Hospital sustains injuries due to tripping on uneven pavements. A survey was undertaken to investigate the type and severity of these injuries.

\section{METHODS}

In a 90-day-period (September-November 1989) data were collected prospectively on 100 consecutive patients with injuries attributed to tripping on uneven pavements. The nature of the injuries was documented with details of investigation, treatment and follow-up together with the road name in which the injury occurred.

Correspondence: Mr Martin T. Hunt, AEE Department, The Royal Sussex County Hospital, Eastern Road, Bmghton BN2 3EW, U.K. 


\section{RESULTS}

Forty-two men and 58 women attended the A\&E with injuries from uneven paving slabs. In patients under 60 years injuries were distributed evenly between men and women, M:F 1·3:1, over 60 years of age the ratio was M:F 1:3. Women were injured most frequently during the morning and afternoon but injuries in men occurred evenly throughout the day. Twice as many women as men were carrying shopping bags at the time of injury.

The frequency of injury was constant throughout the week. Greater numbers of patients presented to A\&E on Mondays and fewer on Sundays. The frequency of injury did not appear to be influenced by weather conditions.

Sixty-eight patients presented with injuries within $12 \mathrm{~h}$, a further 17 within $24 \mathrm{~h}$ and the remaining 15 up to 3 weeks from the time of injury.

The severity of injury warranted radiography in 79 patients, 40 of whom had a fracture or dislocation.

Seven patients required admission, six with fractures requiring operative fixation or manipulation under anaesthesia; one patient was admitted for neurological observations.

Eighteen patients required a plaster of Paris splint, four requiring manipulation in $A \& E$ before immobilization.

The remaining patients (60) had soft tissue injuries; 21 only required advice on self-treatment. In the remaining 39 patients more than one type treatment modality was required. Analgesics were prescribed in $90 \%$ of cases, supporting bandages ir $74 \%$, tetanus toxoid in $62 \%$, suturing in $49 \%$, and antibiotics in $8 \%$.

Follow up was advised in 62 patients: fracture clinic (33), general practition (18), A\&E (7) and physiotherapy (4).

Table 1. Breakdown of injuries received

\begin{tabular}{lrc}
\hline Injury site & Radiology & Fracture/disloc \\
\hline Skull & 2 & 0 \\
Facial bones & 10 & 2 \\
Chest & 2 & 1 \\
Humerus & 8 & 8 \\
Radial head & 2 & 2 \\
Wrist & 15 & 6 (Colles) \\
& & 1 (Scaphoid) \\
Hand/digits & 7 & 2 (Triquetral) \\
Hip & 3 & 5 (3 dislocn) \\
Knee & 5 & 1 \\
& & 3 (3 Patella \\
Ankle & & \multicolumn{2}{c}{ fractures, } \\
Foot & 13 & 4 \\
& 79 & 5
\end{tabular}




\section{DISCUSSION}

A disparity of $1.5 \mathrm{cms}$ in pavement level is sufficient to cause pedestrians to trip and sustain injuries (1), and the cost of injuries as a result of falls due of uneven pavements is high in both human and financial terms. The majority of injuries in this study were of a minor nature. Morbidity occurred from soft tissue injuries (60) in the form of significant scarring (5) and residual pain at 6 months (20). Thirtyfive of the 40 patients who sustained a fracture had lingering discomfort at the fracture site together with residual stiffness.

One patient who sustained a fractured neck of femur requiring fixation died post-operatively.

Considering these figures it is not surprising that $£ 10$ million (David \& Freedman, 1990) in compensation was paid for injuries sustained due to uneven pavements in 1987.

These data obtained in 3 months suggests yearly numbers of injuries from uneven pavements in our department are around 400. Extrapolation to a national level suggests there may be upwards of 60000 cases. As only 10000 claims were lodged in 1987, it appears that only about $17 \%$ of such accidents proceed to claims against the local authority. To a great extent these costs are preventable by footpath maintainence.

The road names of the accident sites were noted in our study to identify local high risk areas. Several roads in close proximity to the hospital were identified but this may be a reflection of easy access to prompt treatment rather than an indication of a dangerous area. Excluding localities close to the hospital no one site seemed more dangerous than another. The road names have been grouped according to post-code and sent to the relevant local authority.

Although our sample is small, similar studies in other A\&E departments would provide a better idea of the general state of the public footpaths. With computerisation of A\&E records and the Home Accident Surveillance Scheme now encompassing leisure accidents it will be possible to gather much larger samples providing epidemiological data for such injuries. It will also be possible to identify those areas where injuries occur most frequently, assisting local authorities in maintainence and hopefully reducing injuries and claims.

\section{CONCLUSION}

Greater maintainence of public footpaths would result in reducing claims for compensation from pedestrians tripping over. Hospital expenses for in-patient stays and out-patient clinics would also be reduced.

\section{REFERENCES}

David H. G. \& Freedman (1990) Injuries caused by tripping over paving stones: an unappreciated problem. British Medical Journal 6727 Vol 300. 